\title{
Pilot study of temporal variations in lead bioaccessibility and chemical fractionation in some Chinese soils
}

\author{
Xiang-Yu Tang a,b,*, Yan-Shan Cui ${ }^{a}$, Jing Duan ${ }^{\mathrm{a}}$, Lily Tang ${ }^{\mathrm{c}}$ \\ a State Key Laboratory of Environmental Chemistry and Ecotoxicology, Research Center for Eco-Environmental Sciences, \\ Chinese Academy of Sciences, Beijing 100085, PR China \\ ${ }^{\mathrm{b}}$ Department of Environmental Hydrology \& Microbiology, Zuckerberg Institute for Water Research, The Jacob Blaustein \\ Institutes for Desert Research, Ben-Gurion University of the Negev, Sede Boqer 84990, Israel \\ ${ }^{c}$ Nanjing Institute of Meteorology, Nanjing 210044, PR China
}

\section{A R T I C L E I N F O}

\section{Article history:}

Received 26 October 2007

Received in revised form 21 February 2008

Accepted 23 February 2008

Available online 29 February 2008

\section{Keywords:}

Lead

Soil

Ageing

Bioaccessibility

Sequential extraction

\begin{abstract}
A B S T R A C T
The effect of ageing, following the addition of $\sim 400 \mathrm{mg} \mathrm{kg}^{-1}$ lead $(\mathrm{Pb})$ as $\mathrm{Pb}\left(\mathrm{NO}_{3}\right)_{2}$, on $\mathrm{Pb}$ bioaccessibility was examined in five typical Chinese soils using a physiologically based extraction test. Sequential extraction was employed to identify the source fraction(s) of bioaccessible $\mathrm{Pb}$ in the soils. Pb bioaccessibility decreased exponentially to nearly steady levels in mildly acidic or alkali ( $\mathrm{pH}$ 6.09-7.43) soils, for both gastric (69.91-71.75\%) and small intestinal (7.53-9.63\%) phases within the first 2-4 weeks and 1-2 months of incubation, respectively; however, it took only $1-2$ weeks for strongly acidic $(\approx \mathrm{pH} 4.5)$ soils to reach nearly steady levels of Pb bioaccessibility (73.01-74.46\% and $10.30-10.98 \%$ in the gastric and small intestinal phases, respectively). In addition to the water-soluble and exchangeable fractions, the carbonate fraction of mildly acidic or alkali soils appeared to be a third main source of bioaccessible $\mathrm{Pb}$ in the small intestinal phase; however, bioaccessible $\mathrm{Pb}$ was likely to derive principally from $\mathrm{Pb}$ in the water-soluble and exchangeable fractions of strongly acidic soils. Bioaccessible $\mathrm{Pb}$ in the gastric phase appeared to derive from all the fractions in all five studied soils, even the residual fraction.
\end{abstract}

(C) 2008 Elsevier B.V. All rights reserved.

\section{Introduction}

Lead $(\mathrm{Pb})$ has been recognized as a contaminant posing threats to both soil quality and human health. Two main sources of Pb contamination of soils are industrial activities, including mining and smelting of nonferrous metals, and historical use of Pb-containing products such as paint, leaded gasoline and pesticides [1].

Exposure to $\mathrm{Pb}$ levels sufficient to produce blood $\mathrm{Pb}$ concentrations of $10-15 \mu \mathrm{g} \mathrm{dL}^{-1}$ has been linked to undesirable developmental outcomes in human fetuses and children [2]. Canfield et al. [3] reported that even below $10 \mu \mathrm{g} \mathrm{dL}^{-1}$, blood Pb levels are inversely correlated to children's IQ scores at 3 and 5 years of age; in fact, associated declines in IQ were greater at these levels than at higher levels, indicating that more children may be adversely affected by environmental $\mathrm{Pb}$ than previously estimated. Researchers with the Chinese Medical Association found that $65 \%$ of 11,348 school children tested had blood $\mathrm{Pb}$ levels above

* Corresponding author at: Department of Environmental Hydrology \& Microbiology, Zuckerberg Institute for Water Research, The Jacob Blaustein Institutes for Desert Research, Ben-Gurion University of the Negev, Sede Boqer 84990, Israel. Tel.: +972 86596901 ; fax: +97286596909.

E-mail address: xiangyu.tang@yahoo.com (X.-Y. Tang). the safe limit of $10 \mu \mathrm{g} \mathrm{dL}^{-1}$ set by the World Health Organization [4].

Soils often act as a sink for heavy metals derived from various anthropogenic sources. Therefore, soil contamination with heavy metals has attracted interest, due to both environmental and health-risk concerns $[5,6]$. Inadvertent oral ingestion of soil is considered an important exposure pathway for metals and other contaminants, especially in children through outdoor hand-tomouth activities [7]. Previous work has reported a range of values for bioavailable contaminant levels in soils, with most values being less than $100 \%$, and the age and physical condition of the soil had a significant impact on contaminant bioavailability in each study $[8,9]$. In the last few decades, the methodology for determining the bioavailability of soil heavy metals to humans has seen rapid development, although no standard method of estimating bioavailability has yet been approved by regulatory agencies. Physiologically based extraction (in vitro) tests, which have been well-validated through comparison with animal (in vivo) tests, have proven to be a fast, cost-effective and reliable approach for estimating the bioavailability of heavy metals in soils to humans [10-13]. In vitro methods have been used to estimate the bioaccessibility of heavy metals (e.g. $\mathrm{Pb}$, cadmium and chromium) in soils near ore smelters, mine tailings and other polluted sites [10-17], as well as to evaluate the effectiveness of soil remediation technologies [18-21]. 
Plant uptake and toxicity of metals can be related to specific fractions of a sequential extraction procedure using progressively harsher reagents to dissolve increasingly refractory forms [22], although some inherent limitations caused by non-selectivity of the reagents and possible re-adsorption of metals during the extraction have been reported [23]. Sequential extraction procedures have been widely employed not only to examine the physicochemical forms of metals and thus enable a better understanding of the processes influencing their availability [24], but also to assess the effectiveness of soil remediation technologies and reveal underlying mechanisms [25,26]. A comparative study of Pb bioaccessibility in 15 soils from Germany with $\mathrm{Pb}$ pools from a sequential extraction procedure showed that the addition of milk could increase $\mathrm{Pb}$ bioaccessibility by depleting the organic Pb pool [17]. Sequential extraction procedures have also been used to investigate temporal changes in added heavy metals in soils [27-29]. The decreasing bioavailability of a metal to a given biological organism as its contact time with the soil increases is often termed "ageing" through specific retention mechanisms which are still not well understood. A number of mechanisms may be operational in trace element retention, and the dominant mechanism may vary with incubation time, as described elsewhere [27-28]. Under worst-case bioavailability scenarios, such as new or ongoing site contamination, there is a clear need to intensively investigate the temporal variations in the health-risk assessment, which could result from temporal variations in the physicochemical forms of heavy metals such as $\mathrm{Pb}$.

Nevertheless, to the best of our knowledge, few investigations in the literature have focused on revealing the effect of the ageing process and its underlying mechanisms on the bioaccessibility of heavy metals such as $\mathrm{Pb}$ in soil. Fendorf et al. [28] reported that $\mathrm{Pb}$ bioaccessibility in the $\mathrm{B}$ horizon of soil from the Oak Ridge National Laboratory site declines rapidly to less than $20 \%$ within 30 days of soil incubation with a mixture of $\mathrm{NaAsO}_{2}, \mathrm{CrCl}_{3}$ and $\mathrm{PbCl}_{2}$ in a $0.001-\mathrm{M} \mathrm{CaCl}_{2}$ matrix at $\mathrm{pH} 3$ in a 1:10 (w:v) soil-to-solution ratio, whereas exchangeable $\mathrm{Pb}$ extracted by $\mathrm{MgSO}_{4}$ is relatively constant with time; however, this study was conducted only in the gastric phase, without further evaluation in the small intestinal phase where the main adsorption process usually occurs [30].

The current study was aimed at revealing temporal variations in $\mathrm{Pb}$ bioaccessibility in some typical soils of China using both a modified physiologically based extraction test (PBET) and a sequential extraction procedure, in an attempt to identify the source fraction(s) of bioaccessible $\mathrm{Pb}$ in soils and the effects of soil properties. Such investigations could be crucial in assessing temporal variations in health risks at either new or historically $\mathrm{Pb}$-contaminated sites.

\section{Materials and methods}

\subsection{Soil preparation}

Five typical uncontaminated soils, including Cryi-Ustic Isohumosol (CC), Hapli-Ustic Argosol (BJ), Ferri-Udic Argosol (NJ), Haplic-Udic Ferrosol (YJ) and Rhodi-Udic Ferralosol (HN), were collected from uncultivated lands located across China, from north to south. Selected chemical and physical soil properties, including the background $\mathrm{Pb}$ concentration, are shown in Table 1. Soils were air-dried, ground and passed through a 2-mm mesh sieve. The chemical form of Pb-containing contaminants in soils is usually highly variable and dependent on the nature of their industrial source. Therefore, the soluble $\mathrm{Pb}$ salt $\mathrm{Pb}\left(\mathrm{NO}_{3}\right)_{2}$ was chosen in this study for addition to the soils in order to reveal $\mathrm{Pb}$-partitioning patterns and their potential relation to temporal variations in bioaccessible $\mathrm{Pb}$ levels following the addition of free $\mathrm{Pb}$ ion. Use of this
Table 1

Selected physical and chemical properties of soils

\begin{tabular}{llllll}
\hline Soil & $\mathrm{CC}$ & $\mathrm{BJ}$ & $\mathrm{NJ}$ & $\mathrm{YJ}$ & $\mathrm{HN}$ \\
\hline $\mathrm{pH}\left(\mathrm{CaCl}_{2}\right)$ & 6.09 & 7.43 & 6.09 & 4.50 & 4.56 \\
$\mathrm{CaCO}_{3}\left(\mathrm{~g} \mathrm{~kg}^{-1}\right)$ & 8.75 & 36.88 & 7.88 & 4.38 & 2.38 \\
Organic carbon $\left(\mathrm{g} \mathrm{kg}^{-1}\right)$ & 15.40 & 41.02 & 26.46 & 3.68 & 4.86 \\
Available P $\left(\mathrm{mg} \mathrm{kg}^{-1}\right)$ & 13.34 & 15.02 & 12.80 & 2.02 & 1.14 \\
$\mathrm{CEC}\left(\mathrm{cmol} \mathrm{kg}^{-1}\right)$ & 22.50 & 15.75 & 23.25 & 10.88 & 6.75 \\
$\mathrm{Fe}\left(\mathrm{g} \mathrm{kg}^{-1}\right)^{\mathrm{a}}$ & 4.22 & 4.04 & 6.51 & 22.56 & 48.85 \\
$\mathrm{Mn}\left(\mathrm{g} \mathrm{kg}^{-1}\right)^{\mathrm{a}}$ & 0.27 & 0.15 & 0.46 & 0.09 & 0.51 \\
$\mathrm{~Pb}\left(\mathrm{mg} \mathrm{kg}^{-1}\right)$ & 12.80 & 29.53 & 36.15 & 20.71 & 21.01 \\
$\mathrm{Particle} \mathrm{size} \mathrm{composition}(\%)$ & & & & \\
$\quad$ Sand $(>0.05 \mathrm{~mm})$ & 5.1 & 5.1 & 4.0 & 0.9 & 3.0 \\
Silt $(0.002-0.05 \mathrm{~mm})$ & 82.2 & 77.3 & 88.1 & 58.8 & 64.3 \\
Clay $(<0.002 \mathrm{~mm})$ & 12.7 & 17.6 & 7.9 & 40.3 & 32.7 \\
Clay minerals & $\mathrm{i}>\mathrm{s}$ & $\mathrm{i}>\mathrm{v}>\mathrm{s}$ & $\mathrm{i}>\mathrm{s}>\mathrm{k}$ & $\mathrm{k}>\mathrm{v}>\mathrm{i}$ & $\mathrm{k}>\mathrm{h}>\mathrm{g}$ \\
\hline
\end{tabular}

Represents free Fe/Mn-oxide.

${ }^{b}$ g, gibbsite; h, hematite; i, illite; k, kaolinite; s, smectite; v, vermiculite.

salt allowed us to avoid involvement of the kinetic dissolution process of some sparsely soluble Pb-containing minerals or chemicals (e.g. cerussite) that may be found in various contamination scenarios. Samples ( $400 \mathrm{~g}$ ) of each soil were artificially spiked with $80 \mathrm{~mL}$ of $\mathrm{Pb}\left(\mathrm{NO}_{3}\right)_{2}$ solution (2000 $\mathrm{mg} \mathrm{Pb} \mathrm{L}^{-1}$ ) to increase the total soil $\mathrm{Pb}$ concentration by about $400 \mathrm{mg} \mathrm{kg}^{-1}$, and then mixed thoroughly. After air-drying and re-homogenizing by $2-\mathrm{mm}$ sieving, $40 \mathrm{~g}$ of subsample was weighed into a plastic cup and kept in the dark at $25^{\circ} \mathrm{C}$. To simulate the wetting-drying cycles in the field, soil moisture was brought back to $15 \%$ from 7 to $8 \%$ by adding double-distilled water on a weekly basis. Soil samples were air-dried 1, 3, 7, 14, 30, 60 and 120 days after the artificial $\mathrm{Pb}$ addition, and then ground gently with a wooden stick. Since it is usually assumed that only soil particles less than $0.25 \mathrm{~mm}$ in diameter adhere to the hands of children [31], only this soil fraction $(<0.25 \mathrm{~mm})$ was used for both the physiologically based extraction test and the sequential extraction.

\subsection{Soil characterization}

Soil $\mathrm{pH}$ was determined in $0.01 \mathrm{M} \mathrm{CaCl}_{2}$ with a $\mathrm{pH}$ meter in a $1: 2.5(\mathrm{w}: \mathrm{v})$ soil-to-suspension ratio after $1 \mathrm{~h}$ of equilibration. Soil contents of carbonate and organic carbon were measured using the acid-neutralization [32] and wet-oxidation [33] methods, respectively. Available $\mathrm{P}$ was determined by extraction with $0.5 \mathrm{M} \mathrm{NaHCO}_{3}$ (adjusted to $\mathrm{pH} 8.5$ ) for $30 \mathrm{~min}$ in a $1: 20$ soil-tosolution ratio [34]. Cation-exchange capacity (CEC) of the soil was measured by $\mathrm{NH}_{4}{ }^{+}$retention after percolation with $1 \mathrm{M} \mathrm{NH}_{4} \mathrm{OAC}$ solution ( $\mathrm{pH}$ 7.0) [35]. Free Fe and Mn oxides were extracted with bicarbonate-citrate-dithionite [36], and their levels determined by inductively coupled plasma-atomic emission spectrometry (ICPAES) or inductively coupled plasma-mass spectrometry (ICP-MS). The background concentration of $\mathrm{Pb}$ in the soil was analyzed by ICPMS after digesting uncontaminated soil samples $(<0.25 \mathrm{~mm})$ with aqua regia (a mixture of concentrated $\mathrm{HNO}_{3}$ and concentrated $\mathrm{HCl}$ in a volumetric ratio of $1: 3$ ) and perchloric acid at $160^{\circ} \mathrm{C}$.

After dispersing the soil with $0.5 \mathrm{M} \mathrm{NaOH}$ for strongly acidic soils $\mathrm{YJ}$ and $\mathrm{HN}$, and with $0.5 \mathrm{M}$ sodium oxalate for higher $\mathrm{pH}$ soils CC, BJ and NJ [37], particle-size composition of the $<0.25-\mathrm{mm}$ size fraction was determined by sieving and weighing for the $0.02-0.25$ $\mathrm{mm}$ fractions and with a laser particle size analyzer (Mastersizer 2000, Malvern Co., Worcestershire, UK) for the $<0.02-\mathrm{mm}$ fraction. Soil clay mineralogy was characterized by X-ray diffraction (XRD) analysis using $\mathrm{Cu} \mathrm{K} \alpha$ radiation. $\mathrm{Mg}$ - and $\mathrm{K}$-saturated samples were scanned at $2^{\circ} 2 \theta \mathrm{min}^{-1}$ on ceramic tiles at $25^{\circ} \mathrm{C}$. The K-saturated tiles were further scanned following heat treatments of 110,300 , and $550^{\circ} \mathrm{C}$ [38]. 


\subsection{Physiologically based extraction test}

The physiologically based extraction test proposed by Ruby et al. [10] was used in this study with a major modification involving the addition of $0.15 \mathrm{M} \mathrm{NaCl}$, as proposed by Rodriguez et al. [7]. Artificial gastric solution was prepared by adjusting $4 \mathrm{~L}$ of deionized water to $\mathrm{pH} 1.5$ with $12 \mathrm{M} \mathrm{HCl}$ and then adding $35.1 \mathrm{~g} \mathrm{NaCl}, 2 \mathrm{~g}$ citrate, $2 \mathrm{~g}$ malate, $1.68 \mathrm{~mL}$ lactic acid, $2 \mathrm{~mL}$ acetic acid and $5 \mathrm{~g}$ pepsin (P7000, Sigma Chemical Co., St. Louis, MO, USA) into the solution. Soil ( $6 \mathrm{~g})$ was added to $600 \mathrm{~mL}$ of artificial gastric solution in a 1-L glass reaction vessel which was approximately four-fifths submerged in a temperature-controlled $\left(37^{\circ} \mathrm{C}\right)$ water bath. The anaerobic condition of the digestive tract was created by constantly diffusing argon gas at $1 \mathrm{~L} \mathrm{~min}^{-1}$ through the solution, and solution $\mathrm{pH}$ was monitored constantly and adjusted to the selected $\mathrm{pH}$ with concentrated $\mathrm{HCl}$ or $\mathrm{NaHCO}_{3}$ powder (rather than saturated $\mathrm{NaHCO}_{3}$ solution to avoid a significant change in solution volume), as necessary, throughout the procedure. After $1 \mathrm{~h}$ in the gastric phase, the artificial gastric solution was modified to the small intestinal solution by adjusting the $\mathrm{pH}$ from 1.5 to 7 with $\mathrm{NaHCO}_{3}$ powder and adding $1.2 \mathrm{~g}$ porcine bile extract (B8631, Sigma Chemical Co., St. Louis, MO, USA) and $0.36 \mathrm{~g}$ porcine pancreatin (P1500, Sigma Chemical Co., St. Louis, MO, USA) to each reaction vessel. The duration of the small intestinal phase was $4 \mathrm{~h}$.

Constant mixing was performed throughout the procedure using paddle stirrers at a speed of approximately $100 \mathrm{rpm}$. After each phase, a $20-\mathrm{mL}$ sample of the suspension was collected using a syringe and centrifuged at $7000 \times g$ for $10 \mathrm{~min}$ before filtering the supernatant through a $0.45-\mu \mathrm{m}$ cellulose-nitrate filter.

All in vitro tests were carried out in duplicate for each soil sample. Soluble $\mathrm{Pb}$ concentration in the artificial digestive solution was analyzed using ICP-AES or ICP-MS.

\subsection{Sequential extraction of soil $\mathrm{Pb}$}

Each soil sample $(1 \mathrm{~g})$ was weighed into a $40-\mathrm{mL}$ polyethylene centrifuge tube, and the sequential extraction proposed by Tessier et al. [39] was conducted at room temperature as follows:

- Fraction 1 (water-soluble): soil sample was extracted for $2 \mathrm{~h}$ with $15 \mathrm{~mL}$ of deionized water.

- Fraction 2 (exchangeable): the residue from fraction 1 was extracted for $1 \mathrm{~h}$ with $8 \mathrm{~mL}$ of $1 \mathrm{M} \mathrm{MgCl}_{2}$ (pH 7.0).

- Fraction 3 (carbonate-bound): the residue from fraction 2 was extracted for $5 \mathrm{~h}$ with $8 \mathrm{~mL}$ of $1 \mathrm{M} \mathrm{NaOAc}$ adjusted to $\mathrm{pH} 5.0$ with acetic acid (HOAc).

- Fraction 4 (Fe/Mn-oxide-bound): the residue from fraction 3 was extracted with $20 \mathrm{~mL}$ of $0.04 \mathrm{M} \mathrm{NH} \mathrm{H}_{2} \mathrm{OH} \cdot \mathrm{HCl}$ in $25 \%(\mathrm{v} / \mathrm{v}) \mathrm{HOAc}$ at $96{ }^{\circ} \mathrm{C}$ with occasional agitation for $6 \mathrm{~h}$.

- Fraction 5 (organic matter-bound): the residue from fraction 4 was extracted with $3 \mathrm{~mL}$ of $0.02 \mathrm{M} \mathrm{HNO}_{3}$ and $5 \mathrm{~mL}$ of $30 \%(\mathrm{v} / \mathrm{v})$ $\mathrm{H}_{2} \mathrm{O}_{2}$ (adjusted to $\mathrm{pH} 2$ with $\mathrm{HNO}_{3}$ ). The mixture was heated to $85^{\circ} \mathrm{C}$ for $2 \mathrm{~h}$, with occasional agitation. A second 3-mL aliquot of $\mathrm{H}_{2} \mathrm{O}_{2}$ ( $\mathrm{pH} 2$ with $\mathrm{HNO}_{3}$ ) was added, and the mixture was heated again to $85^{\circ} \mathrm{C}$ for $2 \mathrm{~h}$ with intermittent agitation. After cooling, $5 \mathrm{~mL}$ of $3.2 \mathrm{M} \mathrm{NH}_{4} \mathrm{OAc}$ in $20 \%(\mathrm{v} / \mathrm{v}) \mathrm{HNO}_{3}$ was added and the sample was diluted to $20 \mathrm{~mL}$ and agitated continuously for $30 \mathrm{~min}$.

- Fraction 6 (residual): the residue from fraction 5 was digested with aqua regia and perchloric acid at $160^{\circ} \mathrm{C}$. A standard reference soil, GSS-1 (National Research Center for Geoanalysis, Beijing, China), was used to verify the acid digestion and instrument performance. The recovery for Pb in GSS-1 was $99.1 \%$.

After each successive extraction, separation was performed by centrifuging at $7000 \times g$ for $10 \mathrm{~min}$. The supernatant was decanted and filtered to remove the plant debris. Before the next extraction, the residue was washed with deionized water by vigorous manual shaking, and the supernatant was then discarded after $10 \mathrm{~min}$ of centrifugation. The $\mathrm{Pb}$ concentration in each fraction was determined by ICP-AES or ICP-MS. The overall recovery of $\mathrm{Pb}$ using the chemical fractionation procedure, as determined by comparing the sum of $\mathrm{Pb}$ determined in all six fractions with a single total $\mathrm{Pb}$ determination, was found to be within the range of 91.5-106.8\%.

\subsection{Statistical analysis}

The correlation analysis was performed using SPSS 10.0 for Windows between $\mathrm{Pb}$ bioaccessibility and single or combined $\mathrm{Pb}$ fraction(s) at different incubation times (7 points) for each soil, as well as between $\mathrm{Pb}$ bioaccessibility (on day 120) and properties or $\mathrm{Pb}$ fraction(s) (on day 120 ) of different soils (5 points).

\section{Results and discussion}

\subsection{Temporal variations in $\mathrm{Pb}$ fractionation in soils}

In all studied soils, even at the first sampling (day 1 ), the addition of $\mathrm{Pb}$ resulted in increased $\mathrm{Pb}$ concentrations in all six soil fractions (Table 2). However, data clearly show that some redistribution of $\mathrm{Pb}$ among the fractions took place during the ensuing incubation (Fig. 1). For soils CC and NJ with their higher $\mathrm{pH}$, the amount of water-soluble $\mathrm{Pb}$ (fraction 1) decreased markedly within the first 1-2 weeks following $\mathrm{Pb}$ addition. In the case of the other soils ( $\mathrm{HN}$, $\mathrm{YJ}$ and $\mathrm{BJ}$ ), only a very small amount of spiked $\mathrm{Pb}$ appeared in this fraction, even on day 1 (Table 2). Nevertheless, there was also a slight and slow decrease in the proportion of water-soluble $\mathrm{Pb}$ during the first 1-2 months of incubation. Generally, the amount of water-soluble $\mathrm{Pb}$ was greater in mildly acidic or alkali soils than in strongly acidic soils after reaching a nearly steady state. Decreases in exchangeable $\mathrm{Pb}$ (fraction 2 ) were also observed during the incubation. The decreases generally occurred more rapidly in the two strongly acidic soils (within 1 week) compared to the mildly acidic or alkali soils (within 2 weeks), except for soil CC. There were differences in the rates at which the proportion of carbonate-bound $\mathrm{Pb}$ (fraction 3) generally decreased with time during the first 1-2 weeks of the incubation. The proportions of Fe/Mn-oxide-bound $\mathrm{Pb}$ (fraction 4 ) in the three mildly acidic or alkali soils increased slightly during the first week; in the two strongly acidic soils, however, this fraction continued to increase at very low rates throughout the incubation. Organic-bound $\mathrm{Pb}$ (fraction 5) increased sharply in soils $\mathrm{BJ}$ and $\mathrm{NJ}$ with their relatively high-organic matter content within the first 1-2 months. Only a very slight increase in organic-bound $\mathrm{Pb}$ was observed for soil CC with its medium level of organic matter during the first 2 months. For the two strongly acidic soils, with low levels of organic matter, organic-bound $\mathrm{Pb}$ increased slightly during the first 2-4 weeks, and then stabilized. Residual $\mathrm{Pb}$ (fraction 6) also increased for all studied soils during the incubation. However, the increases were generally completed within the first 1 or 2 weeks of incubation, the proportions of residual $\mathrm{Pb}$ remaining stable thereafter.

In summary, there were clear changes in the proportional distribution of $\mathrm{Pb}$ in all five studied soils during the first 2 months of incubation with spiked $\mathrm{Pb}$. The proportions of $\mathrm{Pb}$ associated with the weakly bound fractions (fractions $1-3$ ) tended to decrease, with corresponding increases in the other three more strongly binding fractions (fractions 4-6). There were differences in the rates at which this redistribution took place, with the changes generally occurring faster in the YJ and HN soils than in the other three soils, probably due to the former's acidic nature.

Despite the differences in the sequential extraction protocol, the results from this study were in general agreement with those of several previous studies $[27,29,40]$. Here, the magnitude of 
Table 2

$\mathrm{Pb}$ concentrations (mean \pm standard deviation) in the fractions of unpolluted and $\mathrm{Pb}$-spiked soils

\begin{tabular}{|c|c|c|c|c|c|c|}
\hline \multirow[t]{2}{*}{ Soil } & \multicolumn{6}{|c|}{$\mathrm{Pb}$ concentration in each fraction $\left(\mathrm{mg} \mathrm{kg}^{-1}\right)$} \\
\hline & Fraction 1 & Fraction 2 & Fraction 3 & Fraction 4 & Fraction 5 & Fraction 6 \\
\hline \multicolumn{7}{|l|}{$\mathrm{CC}$} \\
\hline Unpolluted & $0.074 \pm 0.002$ & $0.046 \pm 0.002$ & $0.47 \pm 0.02$ & $2.76 \pm 0.03$ & $0.77 \pm 0.01$ & $9.19 \pm 0.07$ \\
\hline Pb-spiked (day 1) & $0.87 \pm 0.02$ & $51.23 \pm 2.07$ & $83.41 \pm 1.50$ & $44.39 \pm 0.96$ & $11.63 \pm 0.95$ & $279.85 \pm 2.73$ \\
\hline Pb-spiked (day 120) & $0.38 \pm 0.02$ & $43.78 \pm 1.00$ & $74.10 \pm 1.43$ & $47.35 \pm 1.44$ & $13.26 \pm 1.17$ & $292.24 \pm 3.31$ \\
\hline \multicolumn{7}{|l|}{ BJ } \\
\hline Unpolluted & $0.037 \pm 0.003$ & $0.045 \pm 0.002$ & $1.15 \pm 0.08$ & $5.28 \pm 0.03$ & $1.30 \pm 0.03$ & $19.68 \pm 0.21$ \\
\hline Pb-spiked (day 1 ) & $0.26 \pm 0.02$ & $6.22 \pm 0.24$ & $123.16 \pm 1.52$ & $46.20 \pm 2.91$ & $12.50 \pm 0.80$ & $251.85 \pm 4.56$ \\
\hline Pb-spiked (day 120) & $0.19 \pm 0.01$ & $1.73 \pm 0.18$ & $125.16 \pm 6.56$ & $52.34 \pm 2.65$ & $18.97 \pm 0.83$ & $284.19 \pm 4.45$ \\
\hline \multicolumn{7}{|l|}{ NJ } \\
\hline Unpolluted & $0.072 \pm 0.003$ & $0.029 \pm 0.002$ & $0.71 \pm 0.02$ & $6.45 \pm 0.05$ & $1.70 \pm 0.03$ & $26.11 \pm 0.40$ \\
\hline Pb-spiked (day 1) & $0.79 \pm 0.01$ & $27.38 \pm 1.16$ & $66.22 \pm 1.75$ & $52.83 \pm 1.00$ & $24.48 \pm 0.76$ & $289.19 \pm 4.61$ \\
\hline Pb-spiked (day 120) & $0.31 \pm 0.03$ & $18.49 \pm 1.21$ & $52.47 \pm 0.95$ & $54.84 \pm 1.17$ & $34.74 \pm 0.73$ & $307.37 \pm 4.50$ \\
\hline \multicolumn{7}{|l|}{ YJ } \\
\hline Unpolluted & $0.038 \pm 0.002$ & $0.042 \pm 0.002$ & $0.59 \pm 0.02$ & $4.81 \pm 0.06$ & $0.65 \pm 0.02$ & $12.83 \pm 0.33$ \\
\hline Pb-spiked (day 1) & $0.15 \pm 0.01$ & $166.01 \pm 5.57$ & $68.23 \pm 1.26$ & $30.50 \pm 1.94$ & $4.19 \pm 0.23$ & $190.02 \pm 2.36$ \\
\hline Pb-spiked (day 120) & $0.06 \pm 0.01$ & $118.92 \pm 2.67$ & $59.72 \pm 2.15$ & $31.33 \pm 1.80$ & $5.15 \pm 0.26$ & $221.60 \pm 1.36$ \\
\hline \multicolumn{7}{|l|}{ HN } \\
\hline Unpolluted & $0.024 \pm 0.003$ & $0.036 \pm 0.001$ & $0.40 \pm 0.01$ & $5.29 \pm 0.02$ & $0.50 \pm 0.01$ & $13.84 \pm 0.16$ \\
\hline Pb-spiked (day 1) & $0.31 \pm 0.01$ & $150.64 \pm 2.00$ & $85.62 \pm 0.83$ & $35.68 \pm 1.74$ & $5.71 \pm 0.33$ & $155.95 \pm 6.52$ \\
\hline Pb-spiked (day 120) & $0.17 \pm 0.02$ & $95.98 \pm 1.40$ & $77.91 \pm 2.20$ & $39.98 \pm 1.25$ & $7.23 \pm 0.19$ & $213.88 \pm 2.53$ \\
\hline
\end{tabular}
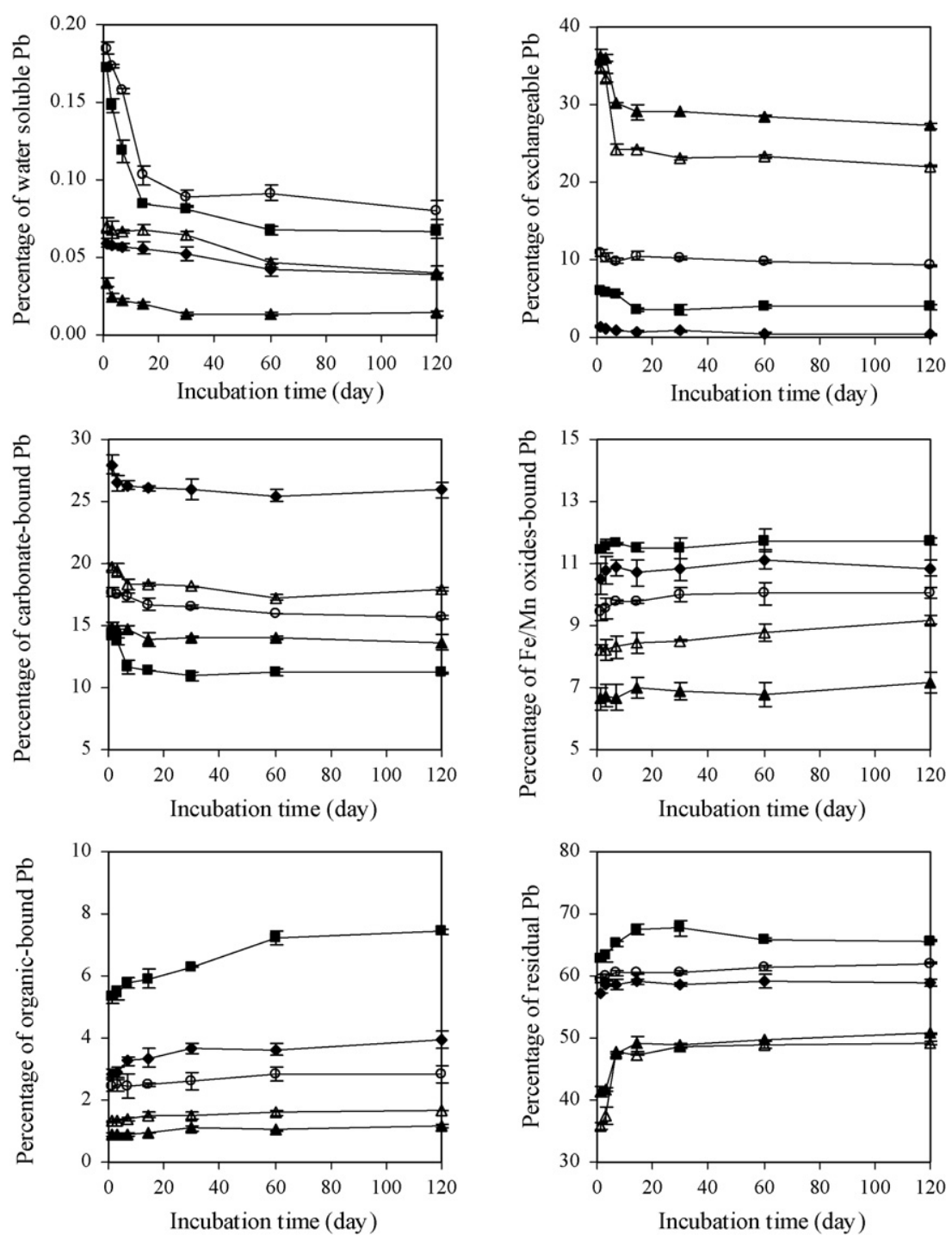

Fig. 1. Variation of $\mathrm{Pb}$ fractionation in soils with incubation time (( $\bigcirc),(\bullet),(\boldsymbol{\square})(\boldsymbol{\Delta})$ and $(\Delta)$ represent soils CC, BJ, NJ, YJ and HN, respectively). 
the decrease in the exchangeable $\mathrm{Pb}$ fraction was much larger in strongly acidic soils than in mildly acidic or alkali soils. Mineral dissolution has been reported to predominate under acidic conditions and to cause a decrease in exchangeable $\mathrm{Pb}$ with time due to the dissolution of Fe oxides [40]. In contrast, a constant level of exchangeable $\mathrm{Pb}$ throughout the entire incubation period was reported by Fendorf et al. [28], a difference which may be due mainly to differences in the method of $\mathrm{Pb}$ addition and subsequent soil incubation. Fendhorf et al. [28] added Pb in a 1:10 (w:v) soil-tosolution ratio and incubated the soil slurry on an orbital shaker for $10 \mathrm{~h}$, providing ideal conditions for $\mathrm{Pb}$ partitioning into the various soil components via the solution phase and the achievement of a nearly steady state within a relatively short time; thereafter, they maintained an approximately 33\% moisture content for the duration of the experiment with no wetting-drying cycle. There were also slight declines in the carbonate fraction of $\mathrm{Pb}$ with time in our study, in agreement with the decreases in the amount of $\mathrm{Pb}$ retained in the carbonate fraction with time at $\mathrm{pH}$ values of $6-8$ observed by Lim et al. [40]. Nevertheless, inconsistent changes in $\mathrm{Pb}$ in the carbonate fraction in three soils from China were reported by Lu et al. [29]. The magnitude of the decrease in exchangeable $\mathrm{Pb}$ in the two strongly acidic soils ( $\mathrm{YJ}$ and $\mathrm{HN}$ ) was close to that of the increase in residual $\mathrm{Pb}$ during the first week, indicating that transformation of exchangeable $\mathrm{Pb}$ to the least available residual $\mathrm{Pb}$ could be a dominant process. In contrast, for mildly acidic or alkali soils (CC, BJ and $\mathrm{NJ}$ ), the loosely bound fractions, i.e. the water-soluble, exchangeable and carbonate fractions, transformed to more strongly bound fractions, particularly the organic and residual fractions, during the first week. It has been reported that water-soluble, exchangeable, and EDTA-extractable (assumed to be specifically sorbed) $\mathrm{Pb}$ in a Mollisol transforms to the easily reducible Mn-oxide- and Fe-oxide-bound forms within 1 month, and the slow process of transformation was attributed mainly to the diffusion of the surface species into micropores and their entrapment in microporous solids [27].

Of all of the soil's properties, $\mathrm{pH}$ and clay minerals appear, in this study, to be the most important factors affecting $\mathrm{Pb}$ redistribution in strongly acidic soils following $\mathrm{Pb}$ addition. Low soil $\mathrm{pH}$ seems to favor the quick redistribution of $\mathrm{Pb}$ from the exchangeable fraction to the residual fraction. The dominant clay mineral, kaolinite, which is a 1:1 clay mineral characterized by relatively low CEC and affinity for heavy metals [41], together with soil $\mathrm{pH}$, were probably responsible for the relatively low level of $\mathrm{Pb}$ in the residual fraction of the two strongly acidic soils in the nearly steady state. In contrast, for the three mildly acidic or alkali soils dominated by $2: 1$ clay mineral(s) having relatively high CEC and affinity for heavy metals [41], more soil factors, including soil $\mathrm{pH}$, carbonate, organic matter and clay minerals, affected $\mathrm{Pb}$ redistribution with time.

There were some clear and major differences between the distributions of indigenous and spiked $\mathrm{Pb}$ in the nearly steady state, but there were also differences between some of the individual soils (Table 2). In the case of indigenous $\mathrm{Pb}$, both concentrations and proportions of the water-soluble, exchangeable, carbonate and organic-bound fractions were very low for all studied soils, with the bulk of the $\mathrm{Pb}$ being distributed between the Fe/Mn-oxide and residual fractions. In particular, the proportion of the dominant residual fraction of indigenous $\mathrm{Pb}$ was over $67.67 \%$ for all studied soils with a mean value of $70.35 \%$. In contrast, the main body of the spiked $\mathrm{Pb}$ appeared in the exchangeable, carbonate, $\mathrm{Fe} / \mathrm{Mn}$-oxide and residual fractions, as indicated in Table 2.

In the nearly steady state, the proportion of exchangeable $\mathrm{Pb}$ was much higher in strongly acidic soils (22.06-27.23\%) than in mildly acidic or alkali soils (0.36-9.29\%). The highest proportion of carbonate-bound $\mathrm{Pb}$ was found in soil $\mathrm{BJ}$ with the highest carbonate content relative to the other four soils. The Fe/Mn-oxide-bound
$\mathrm{Pb}$ fraction in mildly acidic or alkali soils (10.05-11.71\%) was higher than that in strongly acidic soils (7.17-9.19\%) on day 120 , possibly because the lower $\mathrm{pH}$ of the two latter soils make Fe/Mn oxides more positively charged, reducing their ability to bind $\mathrm{Pb}$, despite their higher contents in such soils. Residual Pb levels in mildly acidic or alkali soils were obviously higher than those in the strongly acidic soils in the nearly steady state, possibly as a result of the higher soil $\mathrm{pH}$ and dominance of 2:1 clay minerals in soils CC, BJ and NJ.

There are a number of previous reports characterizing $\mathrm{Pb}$ fractionation in unpolluted and polluted soils using various sequential extraction procedures [27,29]. In an artificially polluted Mollisol, EDTA-extractable (57\%), residual (26\%) and easily reducible Mnbound (10\%) fractions were reported to be the dominant forms of added $\mathrm{Pb}$ [27]. Nevertheless, Lu et al. [29] reported that added $\mathrm{Pb}$ enters mainly the exchangeable, $\mathrm{Fe} / \mathrm{Mn}$-oxide and organic fractions of three soils from China. In sludge-amended soils, $\mathrm{Pb}$ was found to be mainly associated with metal oxides and other soil minerals rather than organic matter, which agrees with other studies on the behavior of $\mathrm{Pb}$ in soils [42]. In two contrasting shooting-range soils (TRR and MPR), residual $\mathrm{Pb}$ was predominant $(20.7 \%)$ in the TRR soil primarily as a result of the formation of hydroxypyromorphite due to the presence of adequate $\mathrm{P}$ in the soil; however, $\mathrm{Pb}$ in the MPR soil was primarily associated with the carbonate fraction (59.8\%), followed by organic $>\mathrm{Fe} / \mathrm{Mn}-$ oxide $>$ residual $>$ water-soluble/exchangeable fractions [43]. Ettler et al. [44] reported that $\mathrm{Pb}$ originating from metallurgical processing is mainly bound to the exchangeable and organic fractions in forest soil; in contrast, it was predominantly associated with the $\mathrm{Fe} / \mathrm{Mn}$-oxide fraction in tilled soil. Generally, the great variations in reported soil $\mathrm{Pb}$ fractionation within each study or among different studies may be attributed not only to the differences in the origin (indigenous or pollution) of the $\mathrm{Pb}$, the pollution source, the soil properties (soil pH, organic matter and clay mineralogy) and the phosphate supply or application, but also to differences in the sequential extraction procedures used. Therefore, our study offers insight into the partitioning and redistribution of spiked free $\mathrm{Pb}$ ions among various soil components in different soil types.

The distribution of added $\mathrm{Pb}$ into the different solid phases may be assumed to be a multistep process involving initial rapid retention followed by secondary slow retention. The rapid retention is initiated by instantaneous adsorption to soil surfaces via the formation of outer-sphere (electrostatic or physical) complexes [28] driven by the concentration gradient from the solution phase to the surface of soil minerals and negatively charged organic matter. Initial adsorbed $\mathrm{Pb}$ is an easily exchangeable fraction, which is retained at a high level at the beginning of the incubation. Therefore, this rapid absorption may have been completed within the 1 day before the monitoring in this study was initiated. Following the rapid absorption, a secondary (slower) shift of $\mathrm{Pb}$ from outer to inner spheres (micropores) [28], possibly involving Fe/Mn oxides, organic matter and the edges of the soil minerals (residual fraction), may occur. Further ageing may lead to more extensive changes, including nucleation and the development of a surface precipitate [45], and occlusion by organic or inorganic materials [46]. Apart from the soil adsorption process, coprecipitation (solid solution) with amorphous Fe oxides and precipitation as pyromorphite upon high $\mathrm{Pb}$ loading and the application of adequate phosphoric acid or phosphate could also effectively contribute to removing $\mathrm{Pb}$ from the solution $[20,21,47]$. The rate of slow retention declines with time to equilibrium among the different $\mathrm{Pb}$ fractions via the soil solution. Therefore, the time needed to approach an apparent equilibrium may be greatly affected by soil $\mathrm{pH}$, clay minerals, Pb-loading rate, organic matter and soluble P content. 

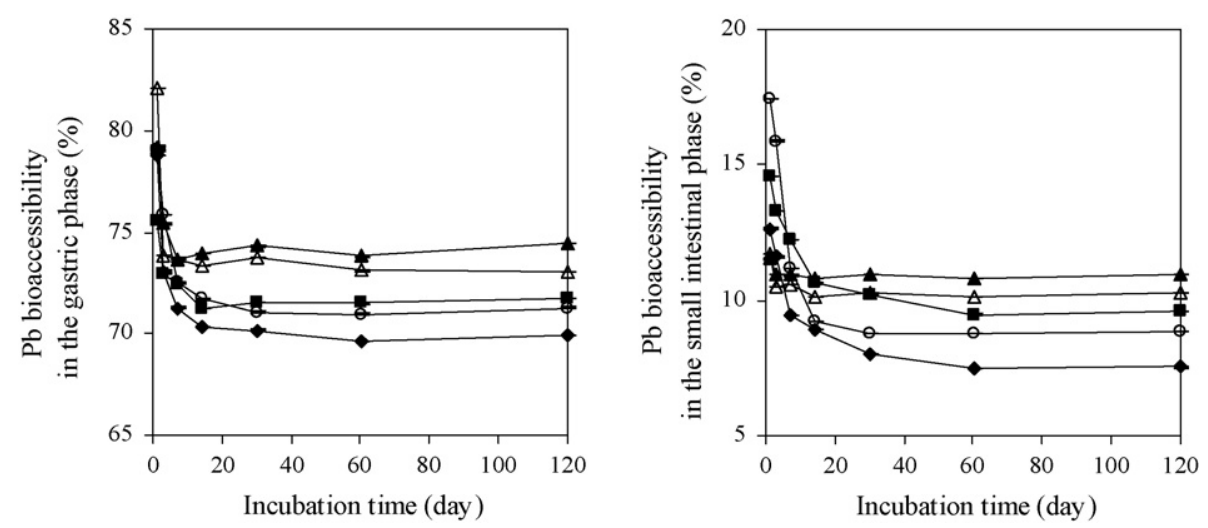

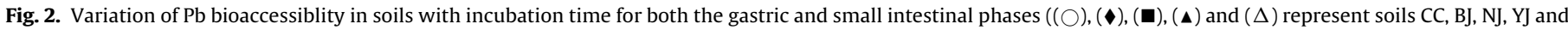
$\mathrm{HN}$, respectively).

\subsection{Temporal variations in $\mathrm{Pb}$ bioaccessibility in soils}

For mildly acidic or alkali soils (CC, BJ and NJ), Pb bioaccessibility decreased exponentially to a nearly steady level in the gastric and small intestinal phases during the first 2-4 weeks and 1-2 months of incubation, respectively; however, it took only 1-2 weeks for the strongly acidic soils (YJ and HN) to reach a nearly steady level of $\mathrm{Pb}$ bioaccessibility in both phases (Fig. 2). In contrast, the decrease in bioaccessibility occurred faster in strongly acidic soils compared with mildly acidic or alkali soils. An exponential decrease in $\mathrm{Pb}$ bioaccessibility of soil in the gastric phase with time within the first 2 weeks was also reported by Fendhorf et al. [28].

$\mathrm{Pb}$ bioaccessibility was lower than $100 \%$ for all five soils in both the gastric and small intestinal phases. In the nearly steady state, $\mathrm{Pb}$ bioaccessibility in both phases in the strongly acidic soils (YJ and $\mathrm{HN}$ ) was also higher than that in the other soils, reflecting the important role of soil $\mathrm{pH}$ in controlling $\mathrm{Pb}$ bioaccessibility (Fig. 2). Bioaccessible $\mathrm{Pb}$ level in soil $\mathrm{BJ}$, characterized by the highest soil $\mathrm{pH}$ at 7.43, appeared to be the lowest at the end of the incubation (day 120). Pb bioaccessibility in soils in both phases followed the same order: $\mathrm{YJ}>\mathrm{HN}>\mathrm{NJ}>\mathrm{CC}>\mathrm{BJ}$. In agreement with the observations by other researchers $[10,19]$, for both polluted and unpolluted soils in this study, $\mathrm{Pb}$ bioaccessibility in the small intestinal phase was markedly lower than that in the gastric phase, possibly resulting from the extensive $\mathrm{Pb}$ adsorption and precipitation at relatively high solution $\mathrm{pH}$ in the small intestinal phase. This suggests that soil $\mathrm{Pb}$ will show higher bioaccessibility in the early stages of pollution, especially in strongly acidic soils that are usually low in organic matter but high in Fe/Mn-oxide contents.

There have been a number of studies estimating $\mathrm{Pb}$ bioaccessibility in soils using various in vitro tests. Ruby et al. [10] reported that dissolution of $\mathrm{Pb}$ in the acidic gastric phase is strongly $\mathrm{pH}-$ dependent, with the extent of dissolution decreasing by $65 \%$ as the gastric $\mathrm{pH}$ increases from 1.3 to 2.5 . On entering the small intestinal phase, $\mathrm{Pb}$ bioaccessibility decreased by $74 \%$ [10]. The addition of phosphorous fertilizers and phosphoric acid was proven to be effective in reducing the bioaccessible and leachable $\mathrm{Pb}$ as a result of its transformation in contaminated soils to (chloro)pyromorphite [18-21]. Moreover, Pb bioaccessibility in 15 soils from Germany was increased from $3-20 \%$ to $11-56 \%$ by the addition of powdered milk, possibly via the formation of soluble $\mathrm{Pb}$ complexes with various milk constituents [17].

$\mathrm{Pb}$ bioaccessibility in unpolluted soils in both phases followed this order ( $\mathrm{Pb}$ bioaccessibility in the gastric phase/Pb bioaccessibility in the small intestinal phase): YJ $(63.48 / 9.07 \%)>\mathrm{HN}(60.17 /$ $8.48 \%)>\mathrm{NJ}(53.09 / 5.91 \%)>\mathrm{CC}(51.43 / 4.22 \%)>\mathrm{BJ}(49.62 / 3.36 \%) . \mathrm{Pb}$ bioaccessibility in unpolluted soils in both phases was much lower than that in artificially polluted soils in the nearly steady state. These observations suggest that the artificially added $\mathrm{Pb}$ is much more labile and bioaccessible than indigenous $\mathrm{Pb}$ and thus poses a greater health risk to humans.

\subsection{The relationship between $\mathrm{Pb}$ bioaccessibility and fractionation in soils}

Correlations between $\mathrm{Pb}$ bioaccessibility and single or combined soil $\mathrm{Pb}$ fraction(s) at different incubation times were determined for each soil, in an attempt to reveal the possible sources of $\mathrm{Pb}$ available for the small intestinal absorption (Table 3). Bioaccessible $\mathrm{Pb}$ was positively related to $\mathrm{Pb}$ in either fractions 1,2 or 3 individually (mostly at significant levels for all of the experimental soils in either digestive phase) or in the sum of fractions 1-3 (always at significant levels for mildly acidic or alkali soils in either phase, and at significant levels for strongly acidic soils in either the gastric or small intestinal phase). $\mathrm{Pb}$ bioaccessibility was negatively related to fraction 6 at significant levels $(P<0.05$ or $P<0.01)$ for mildly acidic or alkali soils but not always significantly for strongly acidic soils in both phases. Nevertheless, it should be noted that neither the proportion of individual fractions 1-3 nor the sum of these three fractions was consistent with bioaccessible $\mathrm{Pb}$ level in the gastric phase with respect to its magnitude and its decline with time.

An additional regression analysis was performed between bioaccessible $\mathrm{Pb}$ and sequentially extracted $\mathrm{Pb}$ fraction(s) or selected soil properties across all the studied soils ( 5 points, day 120), for the data obtained at the final sampling after 4 months of incubation (Table 4). The results showed that $\mathrm{Pb}$ bioaccessibility is positively correlated with $\mathrm{Pb}$ in fraction 2 , in both the gastric $(P<0.05)$ and the small intestinal phase (not at a significant level), across all five soils. Both soil $\mathrm{pH}$ and organic-carbon content was negatively correlated at significant levels to bioaccessible $\mathrm{Pb}$ in both digestive phases, and the content of $\mathrm{CaCO}_{3}$ was negatively correlated $(P<0.05)$ to bioaccessible $\mathrm{Pb}$ level in the small intestinal phase but not in the gastric phase. Moreover, the clay mineralogy also appeared to affect $\mathrm{Pb}$ bioaccessibility, as reflected by the lower levels of bioaccessible $\mathrm{Pb}$ observed in mildly acidic or alkali soils dominated by 2: 1 clay minerals (e.g. illite, smectite and vermiculite) compared with the strongly acidic soils dominated by $1: 1$ clay mineral (e.g. kaolinite) or Fe oxides (e.g. gibbsite and hematite) at the end of the incubation. However, no significant relationship between $\mathrm{Pb}$ bioaccessibility and CEC was observed in this study (Table 4).

We found that throughout the entire incubation time, the sum of $\mathrm{Pb}$ fractions $1-5$ was lower than the bioaccessible $\mathrm{Pb}$ level in the gastric phase but markedly higher than that in the small intestinal phase. It has been reported that soil $\mathrm{Pb}$ bound 


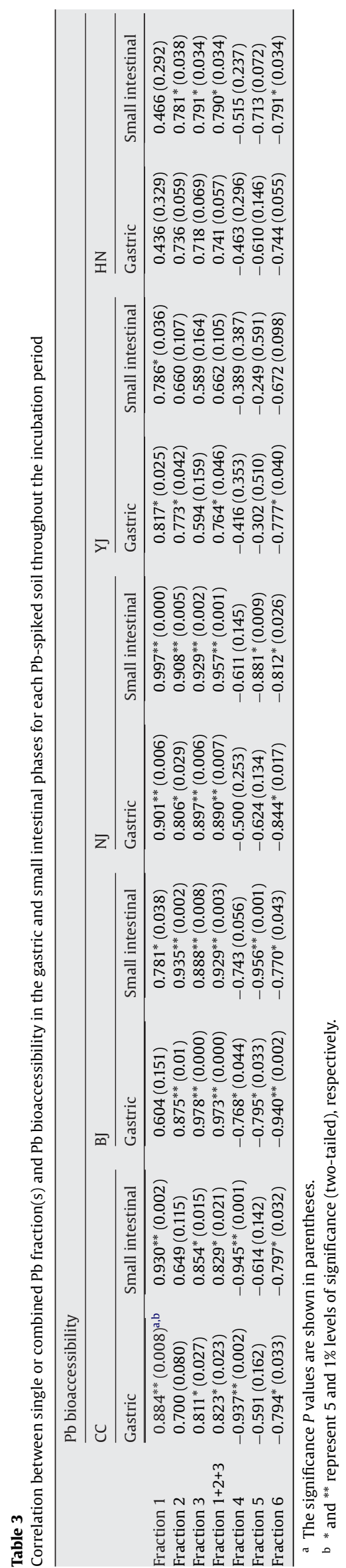

Table 4

Correlation between $\mathrm{Pb}$ bioaccessibility and sequentially extracted $\mathrm{Pb}$ fraction or selected soil properties in the gastric and small intestinal phases after 4 months of incubation

\begin{tabular}{lcc}
\hline & Pb bioaccessibility & \\
\cline { 2 - 3 } & Gastric & Small intestinal \\
\hline Fraction 1 & $-0.560(0.326)$ & $-0.406(0.497)$ \\
Fraction 2 & $0.940^{*}(0.017)^{\mathrm{a}, \mathrm{b}}$ & $0.877(0.051)$ \\
Fraction 3 & $-0.602(0.283)$ & $-0.725(0.166)$ \\
Fraction 4 & $-0.823(0.087)$ & $-0.686(0.201)$ \\
Fraction 5 & $-0.515(0.374)$ & $-0.366(0.545)$ \\
Fraction 6 & $-0.672(0.214)$ & $-0.558(0.328)$ \\
Soil pH & $-0.953^{*}(0.012)$ & $-0.959^{* *}(0.010)$ \\
OC & $-0.889^{*}(0.044)$ & $-0.887^{*}(0.045)$ \\
CEC & $-0.562(0.324)$ & $-0.461(0.435)$ \\
Free Fe oxide & $0.635(0.250)$ & $0.641(0.244)$ \\
Free Mn oxide & $-0.007(0.991)$ & $0.192(0.756)$ \\
CaCO $_{3}$ & $-0.786(0.115)$ & $-0.882^{*}(0.048)$ \\
\hline
\end{tabular}

a The significance $P$ values are shown in parentheses.

b * and ${ }^{* *}$ represent 5 and $1 \%$ levels of significance (two-tailed), respectively.

to carbonate and weak organic complexes, Mn oxides and poorly crystalline Fe-oxihydroxides are significantly depleted by in vitro gastrointestinal-extraction treatment [17]. Therefore, it is likely that the gastric solution, which has a lower $\mathrm{pH}$ (1.5) than the extractants of fractions 1-5 but differs in ionic composition, releases $\mathrm{Pb}$ from soils, via its desorption and/or dissolution, from the carbonate, Fe/Mn-oxide, organic matter and even clay-mineral phases, indicating that bioaccessible $\mathrm{Pb}$ in the gastric phase may come from all soil fractions, even the residual one. Despite the positive relationship between bioaccessible and exchangeable $\mathrm{Pb}$, the difference in $\mathrm{Pb}$ bioaccessibility in the gastric phase among the five studied soils at the end of incubation period was likely due to the difference in binding affinity of the residual fraction for $\mathrm{Pb}$ under acidic conditions. In contrast, the neutral $\mathrm{pH}$ (7.0) of the small intestinal phase, which is identical to the $\mathrm{pH}$ of the extractant of fraction 2 but with higher ionic strength, favors the adsorption of $\mathrm{Pb}$, whereas $\mathrm{Pb}$ dissolution from soil minerals might be very low. To identify the sources of bioaccessible $\mathrm{Pb}$ in soils, in addition to correlation analyses between $\mathrm{Pb}$ bioaccessibility and single or combined $\mathrm{Pb}$ fraction(s) in soils at different incubation times or across different soils at the end of incubation, an additional comparison, of the magnitude of $\mathrm{Pb}$ bioaccessibility and single or combined sequentially extracted soil $\mathrm{Pb}$ fraction(s) was performed. These results showed that, in addition to the water-soluble and exchangeable fractions, the carbonate fraction in mildly acidic or alkali soils appears to be another important source of bioaccessible $\mathrm{Pb}$ in the small intestinal phase; however, in strongly acidic soils, bioaccessible $\mathrm{Pb}$ in the small intestinal phase is likely to derive principally from watersoluble $\mathrm{Pb}$ and a small proportion of exchangeable $\mathrm{Pb}$.

\section{Conclusions}

The bioaccessibility of $\mathrm{Pb}$ added to relatively unpolluted soils decreased exponentially to a nearly steady level in mildly acidic or alkali soils (CC, BJ and $\mathrm{NJ}$ ), this occurred within the first 2-4 weeks for the gastric phase and 1-2 months of incubation for the small intestinal phase. However, it took only 1-2 weeks for the strongly acidic soils ( $\mathrm{YJ}$ and $\mathrm{HN}$ ) to reach a nearly steady level of $\mathrm{Pb}$ bioaccessibility in both phases. Soil pH, clay mineralogy and organic-carbon content were probably the principal factors affecting Pb bioaccessibility once this steady level was attained. However, the content of $\mathrm{CaCO}_{3}$ was found to be negatively correlated $(P<0.05)$ to bioaccessible $\mathrm{Pb}$ levels in the small intestinal phase. At the end of the incubation, the main body of spiked $\mathrm{Pb}$ was found in the carbonate, $\mathrm{Fe} / \mathrm{Mn}$-oxide and residual fractions for mildly acidic or alkali soils, 
whereas for strongly acidic soils, it was found in the exchangeable, carbonate and residual fractions. Soil pH along with clay mineralogy appeared to be the principal factors controlling $\mathrm{Pb}$ redistribution in strongly acidic soils following $\mathrm{Pb}$ addition. In contrast, for mildly acidic or alkali soils, more soil factors, including soil $\mathrm{pH}$, carbonate, organic matter and clay minerals, affected $\mathrm{Pb}$ redistribution with time. Bioaccessible $\mathrm{Pb}$ in the gastric phase appeared to derive from all of the fractions in the soils, even the residual fraction, possibly due to the strong $\mathrm{Pb}$ desorption and/or dissolution from carbonate, Fe/Mn oxides, organic matter and even clay minerals under the highly acidic conditions ( $\mathrm{pH} 1.5$ ) of the simulated gastric solution. In addition to the water-soluble and exchangeable fractions, the carbonate fraction of mildly acidic or alkali soils appeared to be a third main pool of bioaccessible $\mathrm{Pb}$ in the small intestinal phase; however, bioaccessible $\mathrm{Pb}$ was likely to derive principally from $\mathrm{Pb}$ in the water-soluble and exchangeable fractions of strongly acidic soils. Even though China's major soil types were represented in the five soil samples used in this study, future studies using soils from a larger number of sites with different contamination histories are recommended.

\section{Acknowledgements}

The authors would like to acknowledge financial support from the National Foundation of Natural Science of China (Grant No. 20307011), the Chinese Academy of Sciences (KZCX3-SW-424) and Japan Society for the Promotion of Science (P04575).

\section{References}

[1] G.M. Hettiarachchi, G.M. Pierzynski, M.D. Ransom, In situ stabilization of soil lead using phosphorus, J. Environ. Qual. 30 (2001) 1214-1221.

[2] J.M. Davis, D.J. Svendsgaard, Lead and child development, Nature 329 (1987) 297-300.

[3] R.L. Canfield, C.R. Henderson, D.A. Cory-Slechta, C. Cox, T.A. Jusko, B.P. Lanphear, Intellectual impairment in children with blood lead concentrations below $10 \mu \mathrm{g}$ per deciliter, N. Engl. J. Med. 348 (2003) 1517-1526.

[4] C. Washam, Lead challenges China's children, Environ. Health Perspect. 110 (1) (2002) A567.

[5] Y.G. Zhu, S.B. Chen, J.C. Yang, Effects of soil amendments on lead uptake by two vegetable crops from a lead-contaminated soil from Anhui, China, Environ. Int. 30 (2004) 351-356

[6] Y.J. Cui, Y.G. Zhu, R.H. Zhai, Y.Z. Huang, Y. Qiu, J.Z. Liang, Exposure to metal mixtures and human health impacts in a contaminated area in Nanning, China, Environ. Int. 31 (2005) 784-790.

[7] R. Rodriguez, N.T. Basta, S.W. Casteel, L.W. Pace, An in vitro gastrointestinal method to estimate bioavailable arsenic in contaminated soils and solid media, Environ. Sci. Technol. 33 (1999) 642-649.

[8] S.C. Hamel, B. Buckley, P.J. Lioy, Bioaccessibility of metals in soils for different liquid to solid ratios in synthetic gastric fluid, Environ. Sci. Technol. 32 (1998) 358-362.

[9] J.L. Schroder, N.T. Basta, S.W. Casteel, T.J. Evans, M.E. Paytond, J. Si, Validation of the in vitro gastrointestinal (IVG) method to estimate relative bioavailable lead in contaminated soils, J. Environ. Qual. 33 (2004) 513-521.

[10] M.V. Ruby, A. Davis, R. Schoof, S. Eberle, C.M. Sellstone, Estimation of lead and arsenic bioavailability using a physiologically based extraction test, Environ. Sci. Technol. 30 (1996) 422-430.

[11] J.W. Drexler, W.J. Brattin, An in vitro procedure for estimation of lead relative bioavailability: with validation, Hum. Ecol. Risk Assess. 13 (2007) 383401.

[12] M.V. Ruby, Bioavailability of soil-borne chemicals: abiotic assessment tools, Hum. Ecol. Risk Assess. 10 (2004) 647-656.

[13] M.V. Ruby, R. Schoof, W. Brattin, M. Goldade, G. Post, M. Harnois, D.E. Mosby, S.W. Casteel, W. Berti, M. Carpenter, D. Edwards, D. Cragin, W. Chappell, Advances in evaluating the oral bioavailability of inorganics in soil for use in human health risk assessment, Environ. Sci. Technol. 33 (1999) 36973705.

[14] A. Davis, J.W. Drexler, M.V. Ruby, A. Nicholson, Micromineralogy of mine waste in relation to lead bioavailability from the Butte, Montana, Environ. Sci. Technol. 27 (1993) 1415-1425.

[15] J.L. Schroder, N.T. Basta, J.T. Si, S.W. Casteel, T. Evans, M. Payton, In vitro gastrointestinal method to estimate relative bioavailable cadmium in contaminated soil, Environ. Sci. Technol. 37 (2003) 1365-1370.

[16] M.A. Stewart, P.M. Jardine, M.O. Barnett, T.L. Mehlhorn, L.K. Hyder, L.D. McKay, Influence of soil geochemical and physical properties on the sorption and bioaccessibility of chromium(III), J. Environ. Qual. 32 (2003) 129-137.
[17] B. Marschner, P. Welge, A. Hack, J. Wittsiepe, M. Wilhelm, Comparison of soil $\mathrm{Pb}$ in vitro bioaccessibility and in vivo bioavailability with $\mathrm{Pb}$ pools from a sequential soil extraction, Environ. Sci. Technol. 40 (2006) 28122818.

[18] M.V. Ruby, A. Davis, A. Nicholson, In situ formation of lead phosphate in soils as a method to immobilize lead, Environ. Sci. Technol. 28 (1994) 646-654.

[19] P. Zhang, J.A. Ryan, J. Yang, In vitro soil Pb solubility in the presence of hydroxyapatite, Environ. Sci. Technol. 32 (1998) 2763-2768.

[20] J. Yang, D. Mosby, S.W. Casteel, R.W. Blanchar, Lead immobilization using phosphoric acid in a smelter-contaminated soil, Environ. Sci. Technol. 35 (2001) 3553-3559.

[21] X.Y. Tang, Y.G. Zhu, S.B. Chen, L.L. Tang, X.P. Chen, Assessment of the effectiveness of different phosphorus fertilizers to remediate $\mathrm{Pb}$-contaminated soil using in vitro test, Environ. Int. 30 (2004) 531-537.

[22] A. Chlopecka, D.C. Adriano, Mimicked in situ stabilization of metals in a cropped soil: bioavailability and chemical form of zinc, Environ. Sci. Technol. 30 (1996) 3284-3293.

[23] P.M.V. Nirel, F.M.M. Morel, Pitfalls of sequential extractions, Water Res. 24 (1990) 1055-1056

[24] Z.S. Ahnstrom, D.R. Parker, Development and assessment of a sequential extraction procedure for the fractionation of soil cadmium, Soil Sci. Soc. Am. J. 63 (1999) $1650-1658$

[25] D. Turer, A. Genc, Assessing effect of electrode configuration on the efficiency of electrokinetic rernediation by sequential extraction analysis, J. Hazard. Mater 119 (2005) 167-174.

[26] S.B. Chen, Y.G. Zhu, Y.B. Ma, G. McKay, Effect of bone char application on Pb bioavailability in a Pb-contaminated soil, Environ. Pollut. 139 (2006) 433439.

[27] Y.B. Ma, N.C. Uren, Transformations of heavy metals added to soil-application of a new sequential extraction procedure, Geoderma 84 (1998) 157-168.

[28] S. Fendorf, M.J.L. Force, G. Li, Temporal changes in soil partitioning and bioaccessibility of arsenic, chromium, and lead, J. Environ. Qual. 33 (2004) 20492055.

[29] A.X. Lu, S.Z. Zhang, X.Q. Shan, Time effect on the fractionation of heavy metals in soils, Geoderma 125 (2005) 225-234.

[30] P. Mushak, Gastro-intestinal absorption of lead in children and adults: overview of biological and biophysico-chemical aspects, Chem. Speciation Bioavail. 3 (1991) 87-104.

[31] M.J. Duggan, M.J. Inskip, S.A. Rundle, J.S. Moorcroft, Lead in playground dust and on the hands of schoolchildren, Sci. Total Environ. 44 (1985) 65-79.

[32] L.E. Allison, C.D. Moodie, Carbonate, in: C.A. Black (Ed.), Methods of Soil Analysis, Part II, American Society of Agronomy, Madison, Wisconsin, USA, 1965, pp. 1379-1396.

[33] D.W. Nelson, L.E. Sommers, Total carbon, organic carbon, and organic matter in: A.L. Page, R.H. Miller, D.R. Keeney (Eds.), Methods of Soil Analysis, Part II, Second ed., American Society of Agronomy and Soil Science Society of America, Madison, Wisconsin, USA, 1982, pp. 539-579.

[34] S.R. Olsen, L.E. Sommers, Phosphorus, in: A.L. Page, R.H. Miller, D.R. Keeney (Eds.), Methods of Soil Analysis, Part 2, Second ed., American Society of Agronomy and Soil Science Society of America, Madison, WI USA, 1982, pp. 403-430.

[35] H.D. Chapman, Cation-exchange capacity, in: C.A. Black (Ed.), Methods of Soil Analysis, Part II, American Society of Agronomy, Madison, WI, USA, 1965, pp. 891-901.

[36] O.P. Mehra, M.L. Jackson, Iron oxide removal from soils and clays by a dithionitecitrate system buffered with sodium-bicarbonate, Clay Clay Miner. 7 (1960) 317-327.

[37] R.K. Lu, Analytical Methods for Soils and Agricultural Chemistry, China Agricultural Science and Technology Press, Beijing, China, 2000.

[38] L.D. Whittig, W.R. Allardice, X-ray diffraction techniques, in: A. Klute (Ed.), Methods of soil analysis, Part 1, Second ed., American Society of Agronomy and Soil Science Society of America, Madison, WI, USA, 1986, pp. 331-362.

[39] A. Tessier, P.G.C. Campbell, M. Bisson, Sequential extraction procedure for the speciation of particulate trace metals, Anal. Chem. 51 (1979) 844-851.

[40] T.T. Lim, J.H. Tay, C.I. Teh, Contamination time effect on lead and cadmium fractionation in a tropical coastal clay, J. Environ. Qual. 31 (2002) 806-812.

[41] R.W. Puls, H.L. Bohn, Sorption of cadmium, nickel, and zinc by kaolinite and montmorillonite suspensions, Soil Sci. Soc. Am. J. 52 (1988) 1289-1292.

[42] L. Ramos, L.M. Hernandez, M.J. Gonzalez, Sequential fractionation of copper, lead, cadmium and zinc in soils from or near Doñana national park, J. Environ. Qual. 23 (1994) 50-57.

[43] X.D. Cao, L.Q. Ma, M. Chen, D.W. Hardison, W.G. Harris, Lead transformation and distribution in the soils of shooting ranges in Florida, USA, Sci. Total Environ. 307 (2003) 179-189.

[44] V. Ettler, A. Vaněk, M. Mihaljevič, P. Bezdičk, Contrasting lead speciation in forest and tilled soils heavily polluted by lead metallurgy, Chemosphere 58 (2005) 1449-1459.

[45] R.G. Ford, D.L. Sparks, The nature of Zn precipitates formed in the presence of pyrophyllite, Environ. Sci. Technol. 34 (2000) 2479-2483.

[46] A. Filius, T. Strech, J. Ritcher, Cadmium sorption and desorption in limed topsoils as influenced by $\mathrm{pH}$ : isotherms and simulated leaching, J. Environ. Qual. 27 (1998) 12-18.

[47] C.D. Martínez, M.B. McBride, Solubility of $\mathrm{Cd}^{2+}, \mathrm{Cu}^{2+}, \mathrm{Pb}^{2+}$, and $\mathrm{Zn}^{2+}$ in aged coprecipitates with amorphous iron hydroxides, Environ. Sci. Technol. 32 (1998) 743-748. 